07

\title{
Особенности переключения мемристорных структур в высокоомное состояние пилообразными импульсами
}

\author{
(ㄱ Д.О. Филатов, В.В. Карзанов, И.Н. Антонов, О.Н. Горшков
}

Нижегородский государственный университет им. Н.И. Лобачевского, Нижний Новгород, Россия

E-mail: dmitry_filatov@inbox.ru

Поступило в Редакцию 20 сентября 2018 г.

Экспериментально установлено, что время переключения треугольными импульсами в мемристорных структурах $\mathrm{Ti}-\mathrm{TiN}-\mathrm{ZrO}_{2}(\mathrm{Y})-\mathrm{Zr}-\mathrm{Au}$ из низкоомного в высокоомное состояние обратно пропорционально скорости нарастания напряжения на структуре, т. е. току смещения через мемристорную структуру. Предложен механизм влияния силы тока смещения на время переключения.

DOI: 10.21883/PJTF.2018.24.47035.17531

Мемристоры на основе структур металл-диэлектрик-металл (МДМ) наиболее совместимы с традиционным КМОП-процессом и считаются перспективными для создания элементов энергонезависимой памяти, программируемых логических схем и других устройств $[1,2]$. Эффект резистивного переключения (РП) в них заключается в обратимом изменении электропроводности тонкой диэлектрической пленки под действием электрического напряжения соответствующей полярности, приложенного к электродам МДМ-структуры. Общепринятая в настоящее время модель механизма РП в мемристорах на основе оксидов металлов основана на концепции формирования (процесс „SET“) и разрушения (процесс „RESET“) проводящих шнуров (филаментов) между электродами, состоящих из вакансий кислорода, за счет электрохимических реакций окисления-восстановления на интерфейсе металл/диэлектрик под действием внешнего электрического поля [3]. В настоящее время широкому практическому применению мемристоров препятствует нестабильность их электрических параметров [4]. Процессы SET и RESET носят стохастический характер, поскольку размер филамента как в длину, так и в диаметре составляет десятки нанометров, 
а в переключениях участвует лишь ограниченное (малое) количество ионов кислорода (кислородных вакансий) как внутри филаментов, так и на интерфейсе с электродами [5]. Этим обусловлен наблюдаемый в экспериментах разброс параметров РП, включая значения сопротивлений в состоянии с низким сопротивлением (CHC) и состоянии с высоким сопротивлением (СВС). Разность сопротивлений в СВС и СНС зависит от времени воздействия электрического поля на материал диэлектрика, структуры интерфейса, а также от напряжений переключения из СВС в $\mathrm{CHC}\left(U_{\mathrm{SET}}\right)$ и обратно $\left(U_{\mathrm{RESET}}\right)$, при этом важное значение имеет форма импульсов [6,7]. В [8] установлено, что при переключении прямоугольными импульсами соотношение сопротивлений мемристоров на основе структур $\mathrm{Pt} / \mathrm{HfO}_{2} / \mathrm{TiN}$ в $\mathrm{CBC}$ и CHC растет с увеличением длительности импульса, а при переключении треугольными импульсами падает с увеличением длительности переднего фронта. Эффект связан с соотношением скорости нарастания напряженности электрического поля в промежутке между оконечностью филамента и TiN-электродом и скоростью окисления филамента в ходе процесса RESET. Однако другие составляющие процесса РП импульсами различной формы остаются до сих пор недостаточно изученными. В частности, невыясненной остается роль токов смещения, возникающих в мемристорных структурах при различных скоростях изменения напряжения между электродами.

В настоящей работе представлены результаты исследований особенностей РП в мемристорах на базе структур $\mathrm{Ti}-\mathrm{TiN}-\mathrm{ZrO}_{2}(\mathrm{Y})-\mathrm{Zr}-\mathrm{Au}$ под воздействием сигналов треугольной формы различной длительности. Структуры формировались на $\mathrm{Si}$-подложках со слоями металлизации Ті и TiN (толщиной $25 \mathrm{~nm}$ каждый), на которые методом высокочастотного магнетронного осаждения при температуре подложки $T_{g}=300^{\circ} \mathrm{C}$ наносились слои $\mathrm{ZrO}_{2}(\mathrm{Y})\left(\sim 12 \%\right.$ mol. $\left.\mathrm{Y}_{2} \mathrm{O}_{3}\right)$ толщиной $40 \mathrm{~nm}$, поверх которых методом магнетронного осаждения на постоянном токе при $T_{g}=200^{\circ} \mathrm{C}$ наносились слои $\mathrm{Zr}(8 \mathrm{~nm})$ и $\mathrm{Au}(40 \mathrm{~nm})$. Мезы размером $20 \times 20 \mu \mathrm{m}$ формировались с помощью фотолитографии и закрывались защитным слоем $\mathrm{SiO}_{2}$.

Измерения параметров РП проводились при помощи измерительного комплекса NI PXI-1042Q, включающего генератор стандартных сигналов NI PXI-5422, двухканальный осциллограф NI PXI-5122 и источник питания NI PXI-4110. Сигнал с генератора подавался на электроды мемристоров через операционный усилитель. Для ограниче-

Письма в ЖТФ, 2018, том 44, вып. 24 
ния тока через мемристор в СНС использовался ограничитель тока на основе полевого транзистора КП-103Е, шунтированного диодом Д-220.

После процедуры формовки при напряжении $\sim-6 \mathrm{~V}$ наблюдалось биполярное РП (рис. 1, $a$ ). На рис. 1, $b$ представлены циклические вольт-амперные характеристики (BAX), полученные с использованием сигналов треугольной формы. Развертка по напряжению осуществлялась в пределах от -8 до $+6 \mathrm{~V}$, частота варьировалась от 10 до $10^{4} \mathrm{~Hz}$.

Как в СНC, так и в СВС ВАХ в области малых напряжений аппроксимируются полиномами второго порядка, что указывает на протекание инжекционных токов через диэлектрическую пленку по механизму Ламперта [9].

Было установлено, что зависимость времени перехода из СНС в СВС от частоты пилообразного сигнала может быть аппроксимирована формулой

$$
\tau \approx \frac{0.035}{f}
$$

где $f$ - частота (в герцах), $\tau$ измеряется в секундах (рис. 2). В эксперименте переключение из СНС в СВС всегда происходило на восходящем фронте треугольного импульса (то же было отмечено в [8]). При переключении треугольными импульсами напряжение на мемристоре нарастает с постоянной скоростью $(d U / d t=\mathrm{const})$, которая определяется частотой пилообразного сигнала $f$. С учетом этого формула (1) может быть записана в виде

$$
\tau \approx \frac{0.7}{d U / d t}
$$

Здесь $t$ измеряется в секундах, $U-$ в вольтах.

Зависимость (2) указывает на то, что скорость процесса RESET лимитируется силой тока смещения в промежутке между оконечностью филамента и интерфейсом металл/диэлектрик, которая может быть оценена по формуле

$$
j=\frac{\varepsilon \varepsilon_{0}}{\delta} \frac{d U}{d t} .
$$

Здесь $\varepsilon$ - диэлектрическая проницаемость $\mathrm{ZrO}_{2}(\mathrm{Y}), \varepsilon_{0}$ - диэлектрическая постоянная, $\delta$ - толщина зазора между оконечностью филамента и интерфейсом металл/диэлектрик.

Письма в ЖТФ, 2018, том 44, вып. 24 

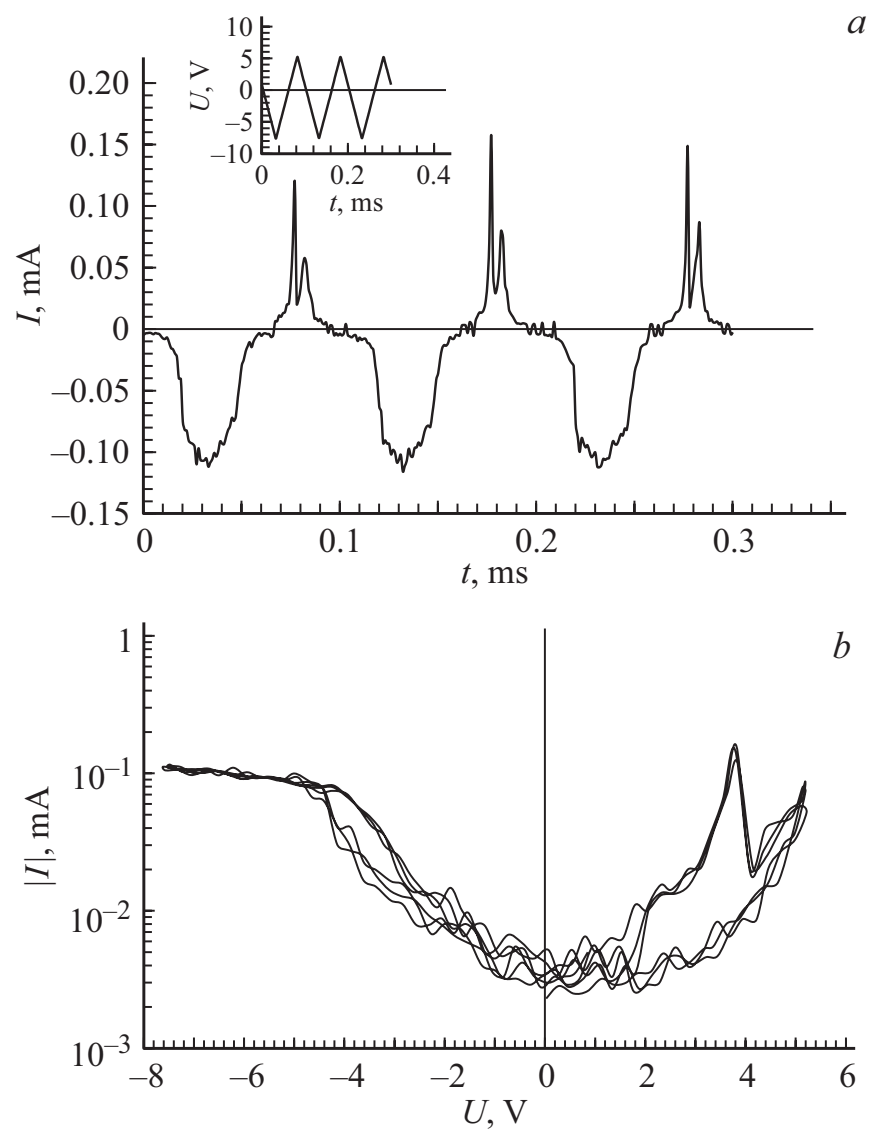

Рис. 1. Осциллограммы переключения мемристорной структуры $(a)$ и ее циклическая BAX $(b)$, измеренная при частоте $10 \mathrm{kHz}$. На вставке показана осциллограмма пилообразного переключающего сигнала.

Следует отметить, что в том случае, когда материал электрода не является химически инертным, на начальной стадии процесса RESET определяющую роль играет обмен ионами кислорода между приповерхностными слоями в интерфейсе [10]. Время формирования диэлектрического слоя определяется характерным временем прыжков

Письма в ЖТФ, 2018, том 44, вып. 24 


$\begin{array}{cccc} & \lg (f, \mathrm{~Hz}) & & 5 \\ 1 & 2 & 3 & 4\end{array}$

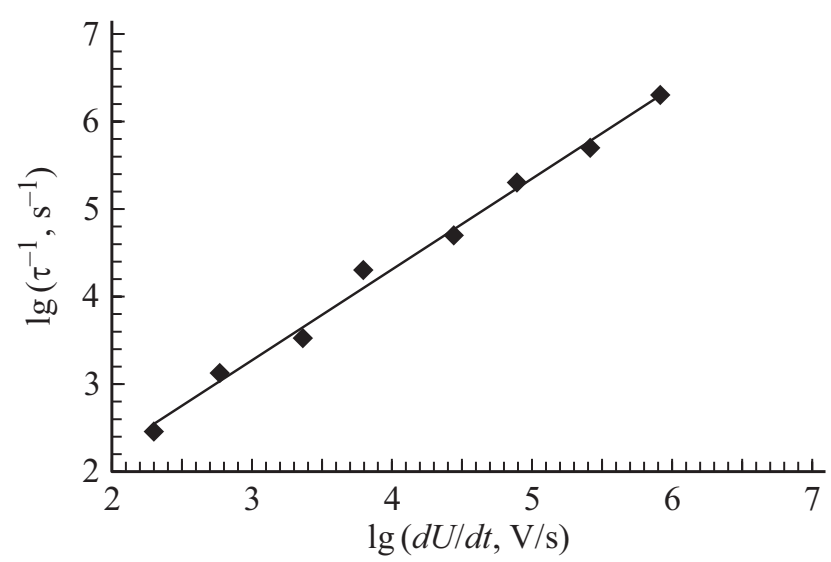

Рис. 2. Зависимость времени переключения из СНС в СВС для мемристора от скорости нарастания напряжения и частоты пилообразного сигнала (шкала частоты указана сверху).

ионов кислорода на соседние вакансии, которое в исследованных образцах может быть оценено по данным [11] как $\sim 10^{-4} \mathrm{~s}$ при $300 \mathrm{~K}$. При этом по мере того, как вакансии кислорода в диэлектрике вблизи интерфейса с электродом заполняются ионами кислорода, становится существенным ток смещения в сформировавшемся диэлектрическом промежутке между интерфейсом металл/диэлектрик и оконечностью филамента. В ходе процесса RESET на оконечности филамента растет положительный заряд вакансий кислорода в связи с уходом электронов из филамента под действием внешнего электрического поля. Электронный ток по филаменту лимитируется током смещения в промежутке между электродом и оконечностью филамента. В свою очередь рост положительного заряда на оконечности филамента ускоряет дрейф ионов кислорода к ней и как следствие увеличивает скорость ее окисления (скорость процесса RESET). Таким образом, чем выше скорость развертки напряжения $d U / d t$ (и в соответствии с (3) ток смещения

Письма в ЖТФ, 2018, том 44, вып. 24 
в промежутке между оконечностью филамента и электродом $j$ ), тем меньше время процесса RESET $\tau$, что и наблюдалось в эксперименте (рис. 2). Принимая в (3) для $\mathrm{ZrO}_{2}(\mathrm{Y}) \varepsilon=20$ и $\delta=5 \mathrm{~nm}$ [12], имеем $j \approx 7 \cdot 10^{-4} \mathrm{~A} / \mathrm{cm}^{2}$ при $f=10 \mathrm{~Hz}$ и $j \approx 0.9 \mathrm{~A} / \mathrm{cm}^{2}$ при $f=10 \mathrm{kHz}$, при этом $\tau$ уменьшается от $350 \mu$ s до $50 \mathrm{~ns}$ соответственно (рис. 2).

Работа выполнена при поддержке РФФИ (грант № 18-42-52059).

\section{Список литературы}

[1] Resistive switching: from fundamentals of nanoionic redox processes to memristive device applications / Eds D. Ielmini, R. Waser. Weinheim: Wiley-VCH, 2016. 784 p.

[2] Merrikh Bayat F., Prezioso M., Chakrabarti B., Nili H., Kataeva I., Strukov D. // Nature Commun. 2018. V. 9. P. 2331.

[3] Riess I. // J. Electroceram. 2017. V. 39. N 1-4. P. 61-72.

[4] Ielmini D. // Semicond. Sci. Technol. 2016. V. 31. N 6. P. 063002.

[5] Lee J.S., Lee S., Noh T.W. // Appl. Phys. Rev. 2015. V. 2. N 3. P. 031303.

[6] Chang K.-C., Chang T.-C., Tsai T.-M., Zhang R., Hung Y.-C., Syu Y.-E., Chang Y.-F., Chen M.-C., Chu T.-J., Chen H.-L., Pan C.-H., Shih C.-C., Zheng J.-C., Sze S.M. // Nanoscale Res. Lett. 2015. V. 10. P. 120-147.

[7] La Torre C., Fleck K., Starschich S., Linn E., Waser R., Menzel S. // Phys. Status Solidi A. 2016. V. 213. N 2. P. 316-319.

[8] Wu C.-H., Lin S.-K., Pan C.-H., Chen P.-H., Lin W.-Y., Chang T.-C., Tsai T.-M., Xu Y.-L., Shih C.-C., Lin Y.-S., Chen W.-C., Wang M.-H., Zhang S.-D., Sze S.M. // IEEE Electron Dev. Lett. 2018. V. 39. N 8. P. 1163-1166.

[9] Ламперт М., Марк П. Инжекционные токи в твердых телах. М.: Мир, 1973. $413 \mathrm{c}$.

[10] Starschich S., Menzel S., Böttger U. // Appl. Phys. Lett. 2016. V. 108. N 3. P. 032903.

[11] Tikhov S., Gorshkov O., Antonov I., Morozov A., Koryazhkina M., Filatov D. // Adv. Condens. Matter Phys. 2018. V. 2018. P. 2028491 (1-8).

[12] Kim W., Menzel S., Wouters D.J., Guo Y., Robertson J., Roesgen B., Waser R., Rana V. // Nanoscale. 2016. V. 8. N 41. P. 17774-17781.

Письма в ЖТФ, 2018, том 44, вып. 24 